\title{
Preparation of Keggin-type Polyoxomolybdate and its Application as Electrochemical Sensor for Detection of Levodopa
}

\author{
Miao Liuł, Mingxuan Jia ${ }^{\dagger}$, Yifeng E, Zhuozhe Li and Donghui Li* \\ Pharmaceutical College, Jinzhou Medical University, Jinzhou, 121001, P.R.China \\ 'Miao Liu and Mingxuan Jia contributed equally to this work. \\ *E-mail: lidonghuilx@sina.com
}

Received: 18 June 2021 / Accepted: 3 August 2021 / Published: 10 September 2021

In this study, a levodopa (LDA) electrochemical sensor based on Keggin-type polyoxometalate was constructed. First, the silicomolybdenum heteropoly acid SiMo12 imidazole was synthesized by hydrothermal method. Fourier transform infrared absorption spectrometry (FTIR), X-ray diffraction (XRD), scanning electron microscopy (SEM) and atomic force microscopy (AFM) were used to characterize the synthetic material. Then the SiMo12 imidazole was dropped onto the surface of a glassy carbon electrode (GCE) to construct an electrochemical sensor for detecting LDA. The sensing interface of the modified electrode was studied by cyclic voltammetry (CV) and electrochemical impedance spectroscopy (EIS). Under the optimal experimental conditions, the constructed electrochemical sensor had good detection performance for LDA with a linear range of $1 \times 10^{-7} \mathrm{~mol} / \mathrm{L} \sim 8 \times 10^{-6} \mathrm{~mol} / \mathrm{L}$ and a limit of detection (LOD) of $0.48 \times 10^{-7} \mathrm{~mol} / \mathrm{L}$. Satisfactory results were also obtained in the detection of LDA tablets.

Keywords: Keggin-type polyoxomolybdate; Levodopa; Electrochemical detection

\section{FULL TEXT}

(C) 2021 The Authors. Published by ESG (www.electrochemsci.org). This article is an open access article distributed under the terms and conditions of the Creative Commons Attribution license (http//creativecommons.org/licenses/by/4.0/). 